\title{
Association of Prediabetes Status Awareness With Behaviors and Perception of Health
}

\author{
Erica Li, MD, Alexis Silverio, MPH, CSCS, CHES, NASM-FNS, \\ Amy Cunningham, PhD, MPH, Marianna D. LaNoue, PhD, MS, and \\ Geoffrey Mills, $M D, P h D$
}

Introduction: Lifestyle modification can significantly reduce the risk of developing diabetes. However, the effect of prediabetes status awareness on perceptions of health and health behaviors are mixed. We used the 2015 to 2016 National Health and Nutrition Examination Survey (NHANES) data to evaluate the association of prediabetes status awareness with self-reported perception of health and health behaviors.

Methods: A secondary analysis was performed on the 2015 to 2016 NHANES, which is a biannual, cross-sectional survey designed to be representative of the civilian, noninstitutionalized United States population. Survey participants were interviewed at home and invited to a mobile examination center to undergo examinations and laboratory measurements. Inclusion and exclusion criteria were applied to create prediabetes-aware and prediabetes-unaware groups. The groups were propensity-score matched based on Body Mass Index, A1c, race, and education. Measures of health perception and health behaviors were analyzed, including feeling at risk for developing diabetes, general health status, perception of weight, desire to lose weight, dietary behaviors, and physical activity behaviors.

Results: Participants who were prediabetes aware were more likely to report a perceived risk of diabetes and to consider themselves overweight. Prediabetes awareness was not associated with any difference in dietary or physical activity behaviors.

Conclusions: Although participants who were aware of their prediabetes status were more likely to report a perceived threat of developing diabetes, they did not report increased engagement in health behaviors. Future research can better understand how these aspects of a health belief model affect engagement in health behaviors for people with prediabetes. (J Am Board Fam Med 2021;34:224-230.)

Keywords: Cross-Sectional Studies, Diabetes Mellitus, Health Behavior, Nutrition Surveys, Obesity, Prediabetes

\section{Introduction}

Approximately one third of adults in the United States have prediabetes, diagnosed by hemoglobin A1c $>5.7 \% .{ }^{1}$ Prediabetes significantly increases the risk of developing diabetes, with up to $11 \%$ of people with prediabetes developing diabetes each year. ${ }^{2}$ Multiple studies have demonstrated the benefit of lifestyle modification in reducing risk of progression to diabetes. ${ }^{2,3}$ Based on these studies,

This article was externally peer reviewed.

Submitted 14 April 2020; revised 3 July 2020; accepted 6 July 2020.

From the Department of Family and Community Medicine, Thomas Jefferson University, Philadelphia, PA (EL, AS, AC, MDL, GM).

Funding: None.

Conflict of interest: None.

Corresponding author: Erica Li, MD, Department of Family and Community Medicine, Thomas Jefferson University, 1015 Walnut Street, Suite 401, Philadelphia, PA 19107, (E-mail: erica.li@jefferson.edu). the Centers for Disease Control and Prevention established the National Diabetes Prevention Program in 2010. The US Community Preventive Services Task Force recommends this approach as an effective intervention to prevent diabetes.

Yet, only about $11 \%$ of people with prediabetes are aware of their condition. ${ }^{1}$ This may be because the term, "prediabetes," is still controversial. ${ }^{4}$ The American Diabetes Association uses "prediabetes" as an umbrella term to encompass impaired glucose tolerance, impaired fasting glucose, and borderline hemoglobin A1c (A1c, 5.7\% to 6.4\%). A 2016 national survey revealed some primary care providers feel that the term may lead to overdiagnosis and overtreatment while others feel it is helpful to engage patients in preventive behaviors. ${ }^{5,6}$

The Health Belief Model, which is commonly used to explain and predict health behaviors, suggests there are 6 constructs that influence adoption 
Figure 1. Applying exclusion criteria to define study populations. *0f the 413 prediabetes-aware participants and the 1041 prediabetes-unaware participants (totaling 1454), 10 participants were excluded for indicating they had more than 1 place for routine care, 5 participants were excluded because they either refused or did not know whether they had health insurance coverage, and 176 were excluded for missing responses to number of health care visits in the past year. Abbreviations: NHANES, National Health and Nutrition Examination Survey; IFG, impaired fasting glucose; IGT, impaired glucose tolerance.

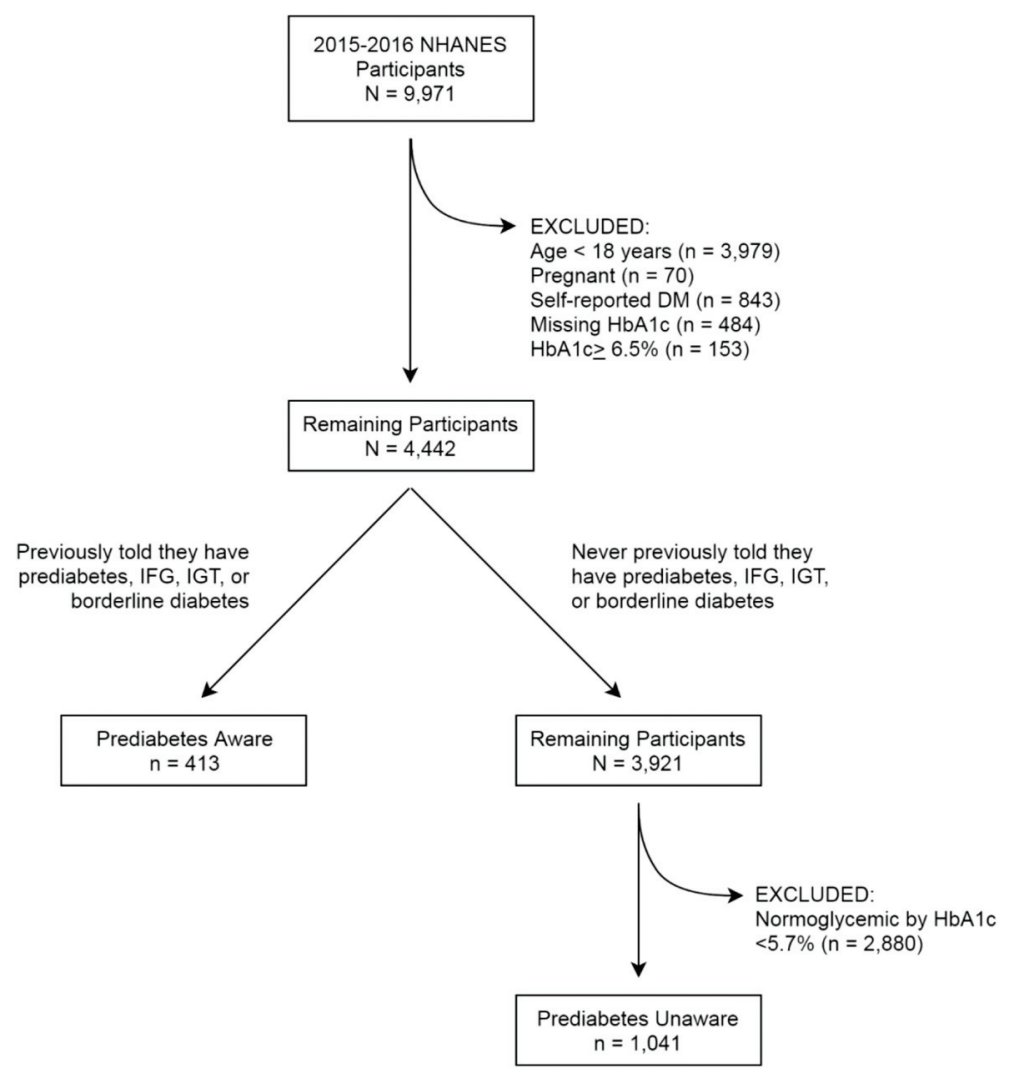

of health behaviors: perceived susceptibility of an illness, perceived severity, benefits of action, barriers to action, self efficacy, and cues to action. ${ }^{7-9}$ In fact, research has shown that a perceived threat of illness correlates positively with engagement in preventive health behaviors. ${ }^{10,11}$

Some studies have explored how awareness of prediabetes status is associated with health behaviors, and there have been discordant findings. In 2015, Gopalan et $\mathrm{al}^{12}$ analyzed the National Health and Nutrition Examination Survey (NHANES) data from 2007 to 2010 and concluded that people aware of their prediabetes status have increased odds of engagement in physical activity and weight management behaviors. However, other studies suggested that prediabetes diagnosis was not associated with increased likelihood of healthy behaviors. ${ }^{13-15}$

In this study, we analyze the most recent NHANES data to provide an updated evaluation of how awareness of prediabetes status is associated with dietary, exercise, and weight behaviors. We expand on the work of Gopalan et $\mathrm{al}^{12}$ by also exploring how prediabetes awareness affects perception of diabetes risk and general health status. We hypothesized that prediabetes status awareness is associated with poorer perception of health and increased engagement in health behaviors, compared with a matched sample of patients who are unaware of their status.

\section{Methods \\ Data}

The NHANES is a cross-sectional survey designed to be representative of the civilian, noninstitutionalized United States population. ${ }^{16,17}$ Data were collected through in-home interviews, standardized physical examinations, and biological specimen collection in mobile examination centers. Sampling used 
the selection of primary units (PSUs), census tract sections within PSU's, households within census tract sections, and persons within households. The data are publicly released and collected in 2-year cycles. We analyzed the 2015 to 2016 NHANES data.

\section{Study Population}

Figure 1 shows application of inclusion and exclusion criteria to arrive at prematched samples. Participants who self reported having diabetes or had diabetes by measured $\mathrm{HbAlc}$ were excluded. Inclusion criteria for the Prediabetes-Aware group included ever having been told they have prediabetes. Inclusion criteria for the Prediabetes-Unaware group included never having been told they have prediabetes and a measured $\mathrm{HbAlc}$ between $5.7 \%$ and $6.4 \%$.

The 2 groups were propensity-score matched, a common approach used to balance groups on an exposure variable, based on Body Mass Index, A1c, race, and education: variables that may affect prediabetes-aware status. ${ }^{18}$ Matching was implemented using 1:1 nearest-neighbor matching without replacement and a fuzzy calipers with a match tolerance of 0.3 . After matching, there were 389 participants in the Prediabetes-Aware group and 410 participants in the Prediabetes-Unaware group, with 21 participants unmatched. Unmatched participants were not included in measures analysis.

\section{Measures}

From the NHANES questionnaires, we chose measures relevant to perceptions of health status and health behaviors that affect prediabetes. We analyzed 4 questions to evaluate perception of health: feeling at risk for developing diabetes, selfreported general health status, self-reported perception of weight, and desire to lose weight. We analyzed 7 questions to evaluate dietary behaviors and 10 questions to evaluate physical activity.

\section{Analyses}

Chi-squared tests for proportions and t-test for continuous variables were performed to determine whether Prediabetes-Aware and -Unaware groups

Table 1. Demographic Characteristics

\begin{tabular}{|c|c|c|c|c|c|}
\hline \multirow[b]{3}{*}{ Characteristics } & \multirow{2}{*}{\multicolumn{2}{|c|}{$\begin{array}{l}\text { Prediabetes Aware } \\
\qquad(\mathrm{n}=410) \\
\end{array}$}} & \multirow{2}{*}{\multicolumn{2}{|c|}{$\begin{array}{l}\text { Prediabetes Unaware } \\
\qquad(\mathrm{n}=389) \\
\end{array}$}} & \multirow{3}{*}{$P$ Value } \\
\hline & & & & & \\
\hline & $\mathrm{n}$ & $\mathrm{M}(\mathrm{SD})$ or $\%$ & $\mathrm{n}$ & $\mathrm{M}(\mathrm{SD})$ or $\%$ & \\
\hline Age (years) & 410 & $53.8(15.3)$ & 389 & $49.6(15.5)$ & .749 \\
\hline \multicolumn{6}{|l|}{ Gender } \\
\hline Male & 176 & $42.9 \%$ & 217 & $55.8 \%$ & \multirow[t]{2}{*}{$<.001$} \\
\hline Female & 234 & $57.1 \%$ & 172 & $44.2 \%$ & \\
\hline \multicolumn{6}{|l|}{ Race } \\
\hline Mexican-American & 60 & $14.6 \%$ & 73 & $18.8 \%$ & \multirow[t]{5}{*}{.095} \\
\hline Other Hispanic & 60 & $14.6 \%$ & 59 & $15.2 \%$ & \\
\hline Non-Hispanic White & 133 & $32.4 \%$ & 116 & $29.8 \%$ & \\
\hline Non-Hispanic Black & 82 & $20.0 \%$ & 92 & $23.7 \%$ & \\
\hline Other race & 75 & $18.3 \%$ & 49 & $12.6 \%$ & \\
\hline \multicolumn{6}{|l|}{ Education level } \\
\hline$<9$ th grade & 42 & $10.3 \%$ & 50 & $12.9 \%$ & \multirow[t]{5}{*}{.003} \\
\hline 9 th to 11 th grade & 36 & $8.9 \%$ & 56 & $14.4 \%$ & \\
\hline High school graduate/GED & 83 & $20.4 \%$ & 94 & $24.2 \%$ & \\
\hline Some college or AA & 123 & $30.3 \%$ & 112 & $28.8 \%$ & \\
\hline College graduate or above & 122 & $30.0 \%$ & 77 & $19.8 \%$ & \\
\hline Routine place for care? (Yes) & 366 & $89.3 \%$ & 299 & $76.9 \%$ & $<.001$ \\
\hline Health insurance coverage? (Yes) & 367 & $89.5 \%$ & 290 & $74.6 \%$ & $<.001$ \\
\hline BMI & 408 & $31.3(7.3)$ & 389 & $30.0(6.9)$ & .198 \\
\hline Alc & 410 & $5.71(0.36)$ & 389 & $5.73(0.05)$ & .279 \\
\hline \# Healthcare visits in past year & 410 & $2.86(1.99)$ & 388 & $2.03(1.8)$ & $<.001$ \\
\hline Had blood test for diabetes within past 3 years? (Yes) & 329 & $80.2 \%$ & 191 & $49.1 \%$ & $<.001$ \\
\hline
\end{tabular}

BMI, Body Mass Index; GED, General Educational Development; SD, standard deviation; AA, Associate of Arts. 
differed with respect to their demographic and clinical characteristics and to their perception of health, dietary, and physical activity outcomes. All analyses were conducted in the matched samples. Criteria were $\alpha=0.002$ for statistical significance. Individual tests were evaluated for significance using a Bonferroni corrected $\alpha=0.002$. SPSS Statistical Software v.26 (IBM, Armonk, NY) was used for data management and analysis.

\section{Results}

\section{Demographics and Characteristics}

Table 1 shows the demographic characteristics of the Prediabetes-Aware and -Unaware groups. Matching was successful in balancing Body Mass Index, A1c, race, and education level between the 2 groups. More prediabetes-aware individuals were female, $(P \leq .001)$ had a routine place for care, had health insurance, and had a blood test for diabetes within the past 3 years $(P \leq .001)$.

\section{Perceptions of Health and Weight}

Table 2 shows responses to health and weight perception items. In the Prediabetes-Aware group, $67.1 \%(n=275)$ felt they could be at risk for diabetes compared with $24.9 \% \quad(n=97)$ in the Prediabetes-Unaware group $(P \leq .001)$.

A higher percentage of the Prediabetes-Unaware group felt their general health status was excellent or very good (41.4\%) compared with the Pre-diabetes-Aware group (32.2\%) $(P=.006)$.

More of the prediabetes-aware individuals considered themselves overweight $(69.3 \%$ vs $51.4 \%)$ and wanted to weigh less $(75.1 \%$ vs $61.7 \%)$ $(P=.001)$. In the Prediabetes-Aware group, 177 $(51.5 \%)$ tried to lose weight in the past 12 months versus $121(35.3 \%)$ in the Prediabetes-Unaware group $(P \leq .001)$.

\section{Dietary Behaviors}

As shown in Table 3, there were no statistically significant differences in any of the responses to dietary behavior items.

As shown in Table 4, the Prediabetes-Unaware group reported spending more time doing moderate activity on a typical day $(P=.001)$; no other comparisons were significant.

\section{Discussion}

We performed a secondary analysis of the 2015 to 2016 NHANES data to investigate whether prediabetes status awareness would impact self-reported perception of health and health behaviors.

Prediabetes awareness was associated with having health insurance, a routine place for care, and more health care visits, thus providing more opportunities for screening, diagnosis, and counseling. Interestingly, despite this, prediabetes awareness

Table 2. Perceptions of Health and Weight

\begin{tabular}{lcc}
\hline & $\begin{array}{c}\text { Prediabetes Aware } \\
\mathrm{n}(\%)\end{array}$ & $\begin{array}{c}\text { Prediabetes Unaware } \\
\mathrm{n}(\%)\end{array}$ \\
\hline Feel could be at risk for diabetes? (\% Yes) & $275(67.1 \%)$ & $97(24.9 \%)$ \\
Self-reported general health status: & & \\
$\quad$ Excellent & $26(6.3 \%)$ & $54(13.9 \%)$ \\
Very good & $106(25.9 \%)$ & $107(27.5 \%)$ \\
Good & $170(41.5 \%)$ & $135(34.7 \%)$ \\
Fair & $90(22.0 \%)$ & $79(20.3 \%)$ \\
Poor & $16(3.9 \%)$ & $14(3.6 \%)$ \\
Don't know & $2(0.5 \%)$ & $0(0.0 \%)$ \\
Self-reported perception of weight: & $284(69.3 \%)$ & $200(51.4 \%)$ \\
Overweight & $108(26.3 \%)$ & $166(42.7 \%)$ \\
About the right weight & $17(4.7 \%)$ & $22(5.7 \%)$ \\
Underweight & & $31(8.0 \%)$ \\
Would you like to weigh more, less, or stay about the same? & $23(5.6 \%)$ & $117(30.1 \%)$ \\
Weigh more & $79(19.3 \%)$ & $240(61.7 \%)$ \\
Stay about the same & $308(75.1 \%)$ & .001 \\
Weigh less & &
\end{tabular}




\begin{tabular}{|c|c|c|c|}
\hline & $\begin{array}{c}\text { Prediabetes } \\
\text { Aware } \\
\mathrm{n}(\%) \text { or } \mathrm{M}(\mathrm{SD})\end{array}$ & $\begin{array}{c}\text { Prediabetes } \\
\text { Unaware } \\
\mathrm{n}(\%) \text { or } \mathrm{M}(\mathrm{SD})\end{array}$ & $\begin{array}{c}P \\
\text { Value }\end{array}$ \\
\hline How healthy is your diet? & & & .155 \\
\hline Excellent & $28(6.8 \%)$ & $25(6.4 \%)$ & \\
\hline Very good & $68(16.6 \%)$ & $76(19.5 \%)$ & \\
\hline Good & $177(43.2 \%)$ & $139(35.7 \%)$ & \\
\hline Fair & $101(24.6 \%)$ & $119(30.6 \%)$ & \\
\hline Poor & $36(8.8 \%)$ & $30(7.7 \%)$ & \\
\hline How many meals were prepared away from home within the past week? & $3.04(3.224)$ & $3.15(3.501)$ & .643 \\
\hline $\begin{array}{l}\text { How many of meals prepared away from home in past week were fast food or } \\
\text { pizza? }\end{array}$ & $1.91(2.356)$ & $2.21(2.787)$ & .148 \\
\hline How often did you get "ready to eat" foods from grocery store in past 30 days? & $2.14(6.596)$ & $2.69(8.933)$ & .324 \\
\hline How often did you eat frozen meals or frozen pizza in past 30 days? & $2.18(4.966)$ & $1.76(5.250)$ & .248 \\
\hline Have you heard of MyPlate? (\% Yes) & $72(17.6 \%)$ & $51(13.1 \%)$ & .133 \\
\hline Have you tried the MyPlate plan? (\% Yes) & $32(44.4 \%)$ & $21(41.2 \%)$ & .718 \\
\hline
\end{tabular}

SD, standard deviation.

was not associated with increased engagement in health behaviors such as physical activity or healthy diet. This is consistent with prior literature, which shows that health insurance, although linked with increased health care utilization, is not associated with change in health behaviors. ${ }^{19}$

We found that prediabetes-aware participants were more likely to report a perceived risk of diabetes, being overweight, and having poorer overall health status. Although prediabetes awareness was associated with higher likelihood of trying to lose weight, the Prediabetes-Aware group was not more likely to engage in healthy dietary or physical activity behaviors. In fact, the Prediabetes-Unaware group reported spending more time on moderateintensity physical activity compared with the Prediabetes-Aware group.

Notably, our findings differ from the Gopalan study, ${ }^{12}$ which found that prediabetes awareness was associated with increased engagement in weight-related behaviors and physical activity. This may be related to our different methods. Gopalan et $\mathrm{al}^{12}$ utilized pooled NHANES data and a traditional regression framework. They created their own measures for weight, physical activity, and combined weight and physical activity behaviors.

Table 4. Exercise Behaviors

\begin{tabular}{lcrl}
\hline & $\begin{array}{c}\text { Prediabetes Aware } \\
\mathrm{n}(\%)\end{array}$ & $\begin{array}{c}\text { Prediabetes Unaware } \\
\mathrm{n}(\%)\end{array}$ & $P$ Value \\
\hline In a typical week, do you: & & & \\
Walk/bike for travel? & $93(22.7 \%)$ & $82(21.1 \%)$ & .513 \\
Do moderate activity? & $178(43.4 \%)$ & $145(37.3 \%)$ & .077 \\
Do vigorous activity? & $83(20.2 \%)$ & $86(22.1 \%)$ & .473 \\
In 1 week, how many days do you: & & & $.29(1.883)$ \\
Walk/bike for travel? & $4.62(1.959)$ & $3.52(1.708)$ & .363 \\
Do moderate activity? & $3.34(1.800)$ & $3.30(1.674)$ & .061 \\
Do vigorous activity? & $3.24(1.582)$ & & .280 \\
On a typical day, time spent: & & $64.82(78.546)$ & .001 \\
Walking/biking & $53.63(56.407)$ & $80.45(81.131)$ & .037 \\
Doing moderate activity & $55.60(47.804)$ & $95.64(66.238)$ & .013 \\
Doing vigorous activity & $73.94(67.593)$ & $353.80(192.356)$ & \\
Time spent sitting on a typical day & $389.26(207.77)$ & & \\
\hline
\end{tabular}


Our study used a propensity score-matching approach and analyzed each measure as found in the NHANES.

Our results can be understood using the Health Belief Model. Our results suggest that the perceived risk of developing diabetes is not enough for people to adopt healthy behaviors. The perceived severity of developing diabetes, benefits to action, barriers to action, self efficacy, and cues to action must also affect engagement in health behaviors. This is consistent with prior studies, in which people who acknowledged a higher risk of developing diabetes and understood how to prevent diabetes still did not adopt healthier lifestyles. ${ }^{13}$

The change in glycemic status from normoglycemic to prediabetes represents an opportunity to change behaviors. Although providing the label of prediabetes increases the perceived threat of developing diabetes, health care providers must also strongly emphasize illness severity and provide cues to action to encourage health behaviors. It is also important to understand the impact of the other constructs of the Health Belief Model and how the constructs interact one another to influence health behaviors. Literature has shown that self efficacy is a hugely important factor in adoption of health behaviors, ${ }^{20,21}$ and that perceived barriers to action have a negative correlation with health behaviors. Unfortunately, the NHANES did not capture robust data on self efficacy, perceived severity of threats, or experiences with cues to action. Future research must explore how these other aspects influence people with prediabetes to engage in health behaviors.

\section{Limitations}

This analysis has several limitations. First, we made no differentiation between participants who had been told they had prediabetes and had forgotten and participants who had never had an Alc test before participating in the NHANES. Second, although we conducted propensity-score matching and attempted various matching schemes, there is a possibility that unmeasured confounders still influenced the data. The cross-sectional nature of the data also limits the ability to accurately capture changes in behavior over time. Finally, selfreported data has the potential for recall bias and social desirability bias. However, this is a large data set, with both self-reported and clinical data, that is nationally representative of the United States.

\section{Conclusion}

We found that participants aware of their prediabetes status were more likely to report a perceived threat of developing diabetes but despite this, participants did not report increased engagement in health behaviors. This may be due to a lack of perceived severity of diabetes, a lack of self efficacy, a lack of benefits to action, significant barriers to action, a lack of cues to action, or social factors. Future steps include conducting mixed-methods investigations to better understand how these other aspects of the Health Belief Model affect engagement in health behaviors for people with prediabetes.

To see this article online, please go to: http://jabfm.org/content/ 34/1/224.full.

\section{References}

1. Centers for Disease Control and Prevention. National Diabetes Statistics Report. Atlanta, GA: Centers for Disease Control and Prevention, U.S. Department of Health and Human Services; 2017.

2. Knowler WC, Barrett-Connor E, Fowler SE, et al. Reduction in the incidence of type 2 diabetes with lifestyle intervention or metformin. N Engl J Med 2002;346:393-403.

3. Tuomilehto J, Lindström J, Eriksson JG, et al. Prevention of type 2 diabetes mellitus by changes in lifestyle among subjects with impaired glucose tolerance. N Engl J Med 2001;344:1343-50.

4. Yudkin JS, Montori VM. The epidemic of pre-diabetes: the medicine and the politics. BMJ 2014;349: g4485.

5. Yudkin JS. "Prediabetes": are there problems with this label? Yes, the label creates further problems! Diabetes Care 2016;39:1468-71.

6. Cefalu WT. "Prediabetes": are there problems with this label? No, we need heightened awareness of this condition! Diabetes Care 2016;39:1472-7.

7. Becker MH. The health belief model and sick role behavior. Health Educ Monographs 1974;2:409-19.

8. Champion V, Skinner C. The health belief model. In: Glanz K, Rimer BK, Viswanath K, eds. Health behavior and health education: theory, research, and practice. 4th ed. San Francisco, CA: Jossey-Bass; 2008: 44-65.

9. Rosenstock IM. Historical origins of the health belief model. Health Educ Monographs 1974;2: 328-35.

10. Norman P, Brain K. An application of an extended health belief model to the prediction of breast selfexamination among women with a family history of breast cancer. Br J Health Psychol 2005;10: $1-16$.

11. Chang LC, Hung LL, Chou YW, Ling LM. Applying the health belief model to analyze 
intention to participate in preventive pulmonary tuberculosis chest $x$-ray examinations among indigenous nursing students. J Nurs Res 2007;15:78-87.

12. Gopalan A, Lorincz IS, Wirtalla C, Marcus SC, Long JA. Awareness of prediabetes and engagement in diabetes risk-reducing behaviors. Am J Prev Med 2015;49:512-9.

13. Chen SF, Lin CC. The predictors of adopting a health-promoting lifestyle among work site adults with prediabetes: health-promoting lifestyle of prediabetes. J Clin Nurs 2010;19:2713-9.

14. Bardenheier BH, Cogswell ME, Gregg EW, Williams DE, Zhang Z, Geiss LS. Does knowing one's elevated glycemic status make a difference in macronutrient intake? Diabetes Care 2014;37:3143-9.

15. Strodel RJ, Chang CH, Khurana SG, Camp AW, Magenheimer EA, Hawley NL. Increased awareness, unchanged behavior: prediabetes diagnosis in a low-income, minority population. Diabetes Educ 2019;45:203-13.

16. CDC. About the National Health and Nutrition Examination Survey. Atlanta, GA: Centers for Disease Control and Prevention; 2017. Available from: https:// www.cdc.gov/nchs/nhanes/about_nhanes.htm. Accessed March 25, 2020.

17. CDC. NHANES questionnaires, datasets, and related documentation. Atlanta, GA: Centers for Disease Control and Prevention. 2020. Available from: https:// wwwn.cdc.gov/nchs/nhanes/. Accessed March 25, 2020.

18. Stuart EA. Matching methods for causal inference: a review and a look forward. Stat Sci 2010;25:1-21.

19. Jerant A, Fiscella K, Tancredi DJ, Franks P. Health insurance is associated with preventive care but not personal health behaviors. J Am Board Fam Med 2013;26:759-67.

20. Lo SWS, Chair SY, Lee FK. Factors associated with health-promoting behavior of people with or at high risk of metabolic syndrome: based on the health belief model. Appl Nurs Res 2015; 28:197-201.

21. Johnson JE, Gulanick M, Penckofer S, Kouba J. Does knowledge of coronary artery calcium affect cardiovascular risk perception, likelihood of taking action, and health-promoting behavior change? J Cardiovasc Nurs 2015;30:15-25. 